\title{
PATIENT SATISFACTION FOLLOWING VITREORETINAL SURGERY
}

\author{
P. M. SULLIVAN ${ }^{1}$, A. J. LUFF ${ }^{1}$, S. A. JULIOUS ${ }^{2}$ and C. R. CANNING ${ }^{1}$ \\ Southampton
}

\begin{abstract}
SUMMARY
A postal questionnaire was used to study patient satisfaction in 149 consecutive patients undergoing vitreoretinal surgery in Southampton. Of the 123 patients who responded, $70(60 \%)$ felt that their vision improved following surgery. Fifty-eight patients $(47 \%)$ stated that their vision was not as good as they had hoped it would be, and multiple logistic regression analysis showed that this response reflected a poorer visual outcome in this group. Despite this, $116(94 \%)$ of those replying stated that the operation had been worth while. All 5 patients who felt that their operations had not been worth while had undergone retinal detachment surgery. This high level of satisfaction may be attributable to realistic expectations, as 116 patients $(94 \%)$ replied that the procedures had been adequately explained.
\end{abstract}

Patient satisfaction surveys are a useful adjunct to the objective assessment of medical treatment. ${ }^{1}$ A previous study has shown a high degree of satisfaction following day case cataract surgery, ${ }^{2}$ which is not unexpected in view of the good visual outcome. Since the visual outcome after vitreoretinal surgery is less predictable and postoperative discomfort generally greater, a patient satisfaction survey was undertaken. To the best of our knowledge there are no published data on patient satisfaction following vitreoretinal surgery.

\section{METHODS}

A postal questionnaire was sent, at least 6 months after discharge, to all 149 patients undergoing surgery in the Southampton Vitreoretinal Unit in 1990, to study attitudes to their surgical care. The questionnaire was modelled on those routinely used for patient satisfaction studies by Southampton District Health Authority (Table I). Large (N18) bold print was used and the patients responded to each question by placing a tick in a box. Patients responding negatively to question $3(\mathrm{Q} 3)$ were labelled as dissatis-

From: ${ }^{1}$ Southampton Eye Hospital; ${ }^{2}$ Department of Medical Statistics and Computing, University of Southampton, Southampton, UK.

Correspondence to: Mr. P. M. Sullivan, Moorfields Eye Hospital, City Road, London EC1V 2PD, UK. fied, while those responding negatively to Q4 were labelled as disappointed. Patients were also encouraged to make comments. Each questionnaire was numerically coded to allow it to be matched with similarly coded clinical data while preserving patient anonymity. These clinical data were retrieved from a prospectively completed clinical database, supplemented where necessary from the case notes, and stored and analysed on a personal computer using a database.

Patients who completed and returned the questionnaire (respondents) were compared with non-respondents using the unpaired $t$-test and Pearson chi-squared statistic. Multiple logistic regression analysis was performed using the SPSS/PC+ computer package ${ }^{3}$ and the log likelihood chi-squared statistic used to assess significance.

\section{RESULTS}

The underlying vitreoretinal pathology is summarised in Fig. 1 and the surgical procedures carried out in Table II. The pre- and post-operative Snellen visual actuities are compared in Fig. 2.

One hundred and twenty-three patients (83\%) responded to the questionnaire, of whom $75(61 \%)$ were male. Non-respondents tended to be younger (mean age 37 years) than respondents (mean age 54 years) $(p<0.001$ by $t$-test) and were mostly male (85\%). There were, however, no significant differences between the two groups in terms of underlying ocular pathology (chi-squared $=5.6$, d.f. $=2, p=0.07$ ) or final visual acuity (chi-squared $=2.04$,

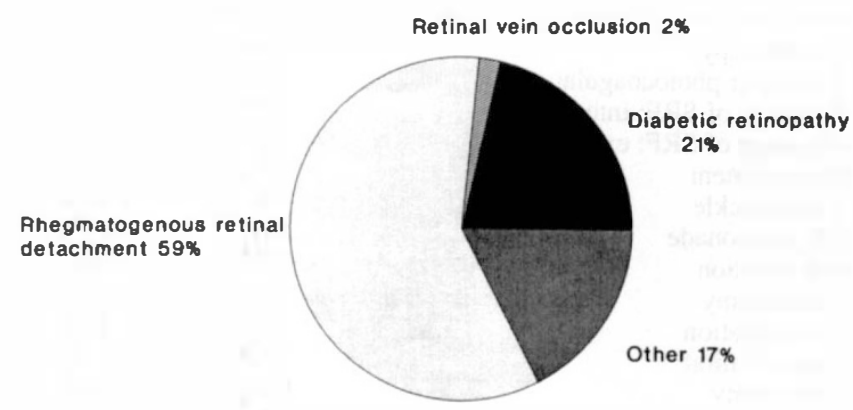

Fig. 1. Underlying ocular pathology in 149 patients undergoing vitreoretinal surgery. 
Table I. Vitreoretinal satisfaction questionnaire: design and responses

\begin{tabular}{|c|c|c|c|c|c|c|c|}
\hline & $\begin{array}{l}\text { Much } \\
\text { better }\end{array}$ & $\begin{array}{l}\text { Slightly } \\
\text { better }\end{array}$ & Same & $\begin{array}{c}\text { Slightly } \\
\text { worse }\end{array}$ & $\begin{array}{l}\text { Much } \\
\text { worse }\end{array}$ & $\begin{array}{l}\text { No } \\
\text { response }^{\mathrm{a}}\end{array}$ & Total \\
\hline \multicolumn{8}{|l|}{$\begin{array}{l}\text { 1. Using your operated eye alone, how is your } \\
\text { vision now compared with before your } \\
\text { operation? (Please ignore this question if you } \\
\text { had operations on both eyes.) }\end{array}$} \\
\hline \multirow[t]{2}{*}{$\begin{array}{l}\text { 2. Using both eyes, how is your vision now } \\
\text { compared with before your operation? }\end{array}$} & $50(41)$ & $20(19)$ & $19(15)$ & $24(20)$ & $9 \quad(7)$ & $1 \quad(1)$ & 123 \\
\hline & \multicolumn{2}{|c|}{ Yes } & \multicolumn{2}{|l|}{ No } & No response & \multicolumn{2}{|r|}{ Total } \\
\hline $\begin{array}{l}\text { 3. Looking back, do you think your operation(s) was/ } \\
\text { were worth while? }\end{array}$ & \multicolumn{2}{|c|}{$116(94)^{\mathrm{b}}$} & \multicolumn{2}{|l|}{$5(4)$} & $2(2)$ & \multicolumn{2}{|r|}{123} \\
\hline 4. Is your vision as good as you hoped it would be? & \multicolumn{2}{|c|}{$65(53)$} & \multicolumn{2}{|l|}{$58(47)$} & $0 \quad(0)$ & \multicolumn{2}{|r|}{123} \\
\hline $\begin{array}{l}\text { 5. Do you feel that you were given an adequate } \\
\text { explanation of the operation and its expected } \\
\text { results? }\end{array}$ & \multicolumn{2}{|c|}{$116(94)$} & \multicolumn{2}{|l|}{$5 \quad(4)$} & $2(2)$ & \multicolumn{2}{|r|}{123} \\
\hline
\end{tabular}

${ }^{a}$ Number of 123 patients returning the questionnaire not answering each question.

${ }^{\mathrm{b}}$ Figures in parentheses are the percentage of 123 respondents giving each response.

d.f. $=2, p=0.25)$. Two non-respondents were found to have died.

The responses to the questionnaire are shown in Table I. The subjective change in binocular visual acuity after surgery (Q2) closely mirrored the subjective change in monocular vision of the operated eye (Q1) in the 109 respondents who had undergone unilateral surgery (chisquared $=186$, d.f. $=16, p<0.0001)$. There was also close agreement between the response to Q1 and the objective change in Snellen visual acuity (chi-squared $=15.5$, d.f. $=$ $4, p<0.01)$.

Five patients $(4 \%)$ felt that the surgery had not been worth while (Q3). All had undergone surgery for rhegmatogenous retinal detachment using an encircling band. Interestingly, 1 of these patients had a final visual acuity of $6 / 9$. In the comments section, dissatisfaction was specifically attributed in 1 case to pain and in 1 case to diplopia. It was not possible to examine factors responsible for dissatisfaction because of the small group size.

Fifty-eight patients (47\%) stated that their post-operative vision was not as good as they had hoped it would be

Table II. Frequency of surgical procedures in 149 patients undergoing vitreoretinal surgery in Southampton in 1990

\begin{tabular}{lcc}
\hline Surgical procedure & Frequency & $(\%)$ \\
\hline Cryotherapy & 91 & $(61)$ \\
Endolaser photocoagulation & 57 & $(38)$ \\
Drainage of SRF: internal & 57 & $(38)$ \\
Drainage of SRF: external & 16 & $(11)$ \\
Encirclement & 35 & $(23)$ \\
Local buckle & 58 & $(39)$ \\
SF tamponade & 70 & $(47)$ \\
Oil insertion & 17 & $(11)$ \\
Lensectomy & 25 & $(17)$ \\
Segmentation & 21 & $(14)$ \\
Delamination & 12 & $(8)$ \\
Vitrectomy & 119 & $(80)$ \\
Membrane peel & 16 & $(10)$ \\
Removal of IOFB & 2 & $(2)$ \\
Retinotomy & 7 & $(5)$ \\
\hline
\end{tabular}

SRF, subretinal fluid; IOFB, intraocular foreign body.
(Q4). Using multiple logistic regression analysis 35 factors were studied for their relationship to this disappointment. These included previous surgery, Snellen visual acuity before and after surgery and in the fellow eye, underlying ocular pathology, the presence of vitreous haemorrhage, the presence of features of retinal detachment, the number of procedures, the presence of bilateral ocular pathology and the responses to the questionnaire. The major determinants of the response to Q4 were the response to $\mathrm{Q} 2$, i.e. subjective visual change (chi-squared $=29.67$, d.f. $=1, p<0.001$ ), and final Snellen visual acuity (chi-squared $=19.58$, d.f. $=1, p<0.001)$. The effect of these two variables was still significant when fitted together. The model with these two variables was able to predict correctly $70 \%$ of all those patients who responded 'no' and $83 \%$ who responded 'yes' to Q4.

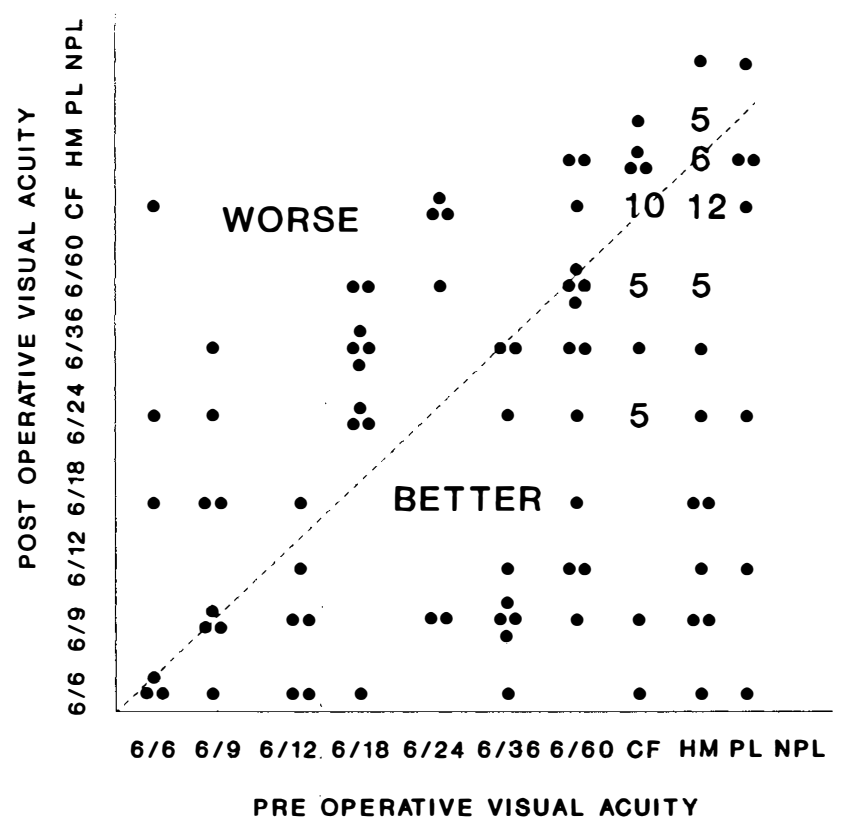

Fig. 2. Scatter diagram of corrected Snellen visual acuity before and after vitreoretinal surgery. 
When post-operative variables were disregarded in order to find a pre-operative (i.e. truly predictive) variable for disappointment, having undergone a previous vitreoretinal operation was significant $(\mathrm{chi}$-squared $=8.72$, d.f. $=$ $1, p=0.003$ ). Sixty-four per cent of patients for whom it was the first operation responded 'yes' to Q4 compared with only $37 \%$ of those who had undergone previous vitreoretinal surgery.

\section{DISCUSSION}

Vitreoretinal procedures are relatively time-consuming and expensive compared with most other ophthalmic operations. While the best justification for this expenditure is provided by objective data such as clinical trials there is clearly merit in determining how patients, as consumers of clinical services, view them. The response to $\mathrm{Q} 3$ indicated a high level of patient satisfaction with vitreoretinal surgery. The small minority $(4 \%)$ who regretted their surgery had all undergone retinal detachment surgery with an encircling band and in at least 2 cases dissatisfaction could be attributed to specific complications (pain and diplopia). This interpretation must be made cautiously because of the small number of patients in this group.

Despite the almost overwhelming opinion that their vitreoretinal operations had been worth while, almost half of the patients replied that their vision was not as good as they had hoped it would be (Q4). As one would expect, this group had poorer post-operative visual acuity. They also tended to have undergone multiple vitreoretinal procedures, and a warning of the possibility of poor vision post-operatively may be especially useful in this group of patients in the future.

Most of the patients replied that the surgery had been well explained (Q5) and there were a great many comments expressing satisfaction with this and other interpersonal aspects of their care. Only 1 of the 5 patients who felt that their surgery was not worth while stated that the procedure had not been adequately explained, suggesting that dissatisfaction with communication did not contribute to overall dissatisfaction. Further work may clarify the cause of this dissatisfaction so that it can be minimised.

Key words: Patient satisfaction, Retinal detachment, Vitrectomy.

\section{REFERENCES}

1. Hopkins A. Measuring the quality of medical care. London: Royal College of Physicians, 1992:55-9.

2. Ingram RM, Bannerjee D, Traynar MJ, Thompson R. Day case cataract surgery. Br J Ophthalmol 1983;67:278-81.

3. Norusis MJ. SPSS/PC+advanced statistics 4.0. USA: SPSS Inc., 1990. 